\title{
How Can History of Science Matter to Scientists?
}

\author{
By Jane Maienschein,* Manfred Laubichler, ** and Andrea Loettgers***
}

\begin{abstract}
History of science has developed into a methodologically diverse discipline, adding greatly to our understanding of the interplay between science, society, and culture. Along the way, one original impetus for the then newly emerging discipline-what George Sarton called the perspective "from the point of view of the scientist"-dropped out of fashion. This essay shows, by means of several examples, that reclaiming this interaction between science and history of science yields interesting perspectives and new insights for both science and history of science. The authors consequently suggest that historians of science also adopt this perspective as part of their methodological repertoire.
\end{abstract}

I N THIS ESSAY we explore the question of what difference the history of science can 1 make for scientists, working in the lab, doing science. We purposely do not offer general prescriptions about the value of history for science; rather, we present some concrete examples and suggest some conclusions that warrant further study and testing. Our approach is a response to earlier answers to this question that we see as too schematic and lacking in detail. If we truly want history of science to have a broader impact in everyday science and with practicing scientists, we need to get beyond sweeping views and look at particular cases and their implications. Yet it is worth reminding ourselves briefly what these earlier suggestions offered, so that we can respond and build further most effectively.

George Sarton, one of the founders of the modern discipline of history of science, emphasized that one of its perspectives represents the "point of view of the scientist." 1 The others were, of course, those of the historian and the philosopher. According to Sarton, history offers scientists a critical point of view that allows them to understand the

* Center for Biology and Society, School of Life Sciences, Arizona State University, Tempe, Arizona 85287-4501.

** Center for Biology and Society and Center for Social Dynamics and Complexity, School of Life Sciences, Arizona State University, Tempe, Arizona 85287-4501.

*** Center for Biological Circuitry Design, California Institute of Technology, Pasadena, California 91125.

${ }^{1}$ George Sarton, "An Institute for the History of Science and Civilization," Science, 1917, 45:284-286, 46:399-402, on p. 400 .

Isis, 2008, 99:341-349

(C)2008 by The History of Science Society. All rights reserved.

0021-1753/2008/9902-0007\$10.00 
interrelations among different disciplines and approaches and therefore helps them to overcome the dangers of mere "empiricism."

In 1974, Stephen Brush asked "Should the History of Science Be Rated X?" He focused on the generation of future scientists and the role of history in science education, suggesting that perhaps history undercuts the treasured myths of how science works and will "do violence to the professional ideal and public image of scientists as rational, open-minded investigators, proceeding methodically, grounded incontrovertibly in the outcome of controlled experiments, and seeking objectively for the truth, let the chips fall where they may." Brush was writing at a time when history of science and the historians writing it still remained close to the science. Often they were scientists by training, though the professionalization of the field was already bringing new Ph.D. graduates with historical or philosophical backgrounds into the field. This matters because of the sets of assumptions the scholars carried. Brush pointed to various efforts to bring history into the teaching of science and some of the "subversive" impacts of such approaches. He acknowledged the tensions in the fact that retrospectively directed whiggish history is what the science teacher wants, while historians are exhorted to avoid such whiggism. "The result," Brush noted in 1974, "is a widening gap between the goals of the historian and of the science teacher." 2

In 2000, Jane Maienschein published a revision of her Sarton Lecture, presented at the 1996 American Association for the Advancement of Science meeting in collaboration with the History of Science Society. By that time, the professional field of history of science had changed considerably. As Polly Winsor noted in an essay published later, proper historians knew to avoid whiggism and even to avoid serving as handmaidens to the will of scientists and science educators. The field had intentionally moved away from science, and Maienschein was concerned about that fact. She offered several suggestions-basically the traditional answers to the question, Why study history of science?- clustered into five categories, suggesting that history might promote

-Self-improvement, illuminating science and making it better

-Efficiency, avoiding and learning from past mistakes

-Perspective, providing judgment and clarity and therefore making science better

-Imagination, offering a wider repertoire of ideas to choose from

-Education, improving public understanding of science and scientific literacy. ${ }^{3}$

This was a start in approaching the question, but only a start. It remained to cash out what each of these claims really meant, whether these traditional arguments were the best or only ways in which history of science might matter for science, and whether we have concrete examples. In this essay, we turn to concrete examples and what they show. We feel that it is time to rebuild the close connections between history and science that can, under the right circumstances and with the right approaches, illuminate and improve both fields.

\footnotetext{
${ }^{2}$ Stephen G. Brush, “Should the History of Science Be Rated X?" Science, 1974, 183:1164-1171, on pp. 1164, 1170 .

${ }^{3}$ Mary P. Winsor, "The Practitioner of Science: Everyone Her Own Historian," Journal of the History of Biology, 2001, 34:229-245; and Jane Maienschein, "Why Study History for Science?" Biology and Philosophy, 2000, 15:339-348, on p. 342.
} 


\section{INTERSECTIONS OF HISTORY AND SCIENCE}

We begin in this section with a brief introduction to three examples taken from personal experience. Each presents an instance where thinking about history made a difference, sometimes in small ways and sometimes in promoting different ways of thinking. In no case is the history being distorted in any way or serving a merely instrumental value for the science. Rather, in each case the work remains true to the highest standards of historical scholarship. Each exemplary case relates to developmental biology, and each warrants examination in more detail.

The first example is Ross Granville Harrison's tissue culture experimental work, published in 1907-1910 and now recognized as the first stem-cell experiment, though it was not called that at the time. The story begins as Maienschein was carrying out her dissertation research, asking in what sense the particular experiment had served as a "crucial experiment" in resolving the long-standing debate about epigenesis versus preformation. Some biologists argued that the nerve fibers that make up the complex nervous system are already in the egg cell from the beginning and just grow out along preestablished bridges. Camillo Golgi was one of these, and he developed wonderful silver nitrate preparations for staining neural tissue to provide evidence for his interpretation. At the same time, others—such as Santiago Ramón y Cajal—made equally excellent preparations, sometimes using the same techniques, but saw something quite different. Ramón y Cajal saw the complex system emerging gradually, as each cell found its independent path. ${ }^{4}$

Harrison realized that the only way to resolve the debate would be through some different approach - specifically, with a controlled experimental manipulation of the neuroblast cells. He carried out the experiment, which demonstrated that nerve fibers have the capacity to stretch through outgrowth and take on the shapes they do in normal conditions. The experiment was quickly labeled as crucial and won the day for the epigenetic interpretation.

Maienschein replicated Harrison's experiment as exactly as possible in order to understand better what he did and the choices he made. The embryologist on her doctoral committee, Robert Briggs (who along with Thomas King is well known for doing the first frog cloning in the 1950s), helped. He guided her in setting up the lab, cutting out neuroblast cells, and establishing the frog lymph cultures that Harrison described. They grew various wandering microbiological things, some quite beautiful, but never nerve cells. Harrison clearly had not made this up, so what was going wrong? Maienschein went back to Harrison's archival notes and to the records at Johns Hopkins (where he had gotten the procedure to work once) and at Yale (where he reported that the process was much more successful). It turned out that when Harrison first arrived at Yale, his lab was not ready for him. He set up temporarily near the bacteriologists and apparently learned bacteriological techniques for maintaining aseptic conditions. ${ }^{5} \mathrm{He}$ never recorded what has since been called the "tacit knowledge," but Maienschein and Briggs discovered the importance of the details of the practice.

The point here is not just that replicating historical experiments is fun and involves detective work. What is interesting is Briggs's reaction. He noted that this leading

\footnotetext{
${ }^{4}$ For further discussion see Jane Maienschein, "Experimental Biology in Transition: Harrison's Embryology, 1895-1910," Studies in History of Biology, 1983, 6:107-127.

5 Jane Maienschein, "Ross Harrison's Crucial Experiment as a Foundation for Modern American Experimental Embryology” (Ph.D. diss., Indiana Univ., 1978).
} 
experimental embryologist, even in his most famous research publications, had made important assumptions that he had not recorded. Briggs, in turn, realized that he had made assumptions about how the experiment was done. Being aware of the value of examining basic assumptions wherever possible can improve scientific work. Briggs noted that this case reminded him to examine his assumptions, and he reported the lesson to his students. This historical case reinforced the lesson learned when he had assumed that nuclear transplantation in frogs can work successfully only in the very earliest egg stages but John Gurdon had shown a decade later that such cloning could occur with later-stage eggs as well. And though Briggs had died by then, the birth of Dolly the cloned sheep in 1997 demonstrated - contrary to earlier assumptions-that even somatic cells could be transferred and could develop into a normal sheep. The historical example showed dramatically the value of accident (Harrison's being placed temporarily next to the bacteriologists) and the significance of assumptions.

A second example is Viktor Hamburger's study of his dissertation advisor Hans Spemann. Hamburger was an excellent neuroembryologist at Washington University in St. Louis, and after he retired he spent many hours talking about the history of embryology with the historian Garland E. Allen, his friend and colleague. Allen helped persuade Hamburger to write up his story, and they devised the approach of writing as narrative all the parts that were documented and met the highest standards of historical scholarship. But Allen did not want to lose Hamburger's own recollections, so Hamburger included these in italics interspersed through the rest of the story.

Hamburger was already retired, so his turning to history did not inform his own scientific work. But he wanted scientists to read his biographical study of Spemann, and he wanted to make two main points. First, he felt strongly the importance of giving appropriate credit for work done. Part of his motivation for writing the book, he reported, was his wish to give Hilde Pröscholdt Mangold the credit she deserved for carrying out the experiment for which Spemann received a Nobel Prize. He did not deny that Spemann deserved the prize, but he wanted to explain the nature of the work and the relative contributions to it. This was especially instructive, since many embryologists felt that Hamburger deserved his own Nobel Prize for his work on nerve growth factor done in his lab and by researchers who over time have given him less and less credit. The second lesson Hamburger wanted to get across was the messiness of study of the tissue that came to be called the "organizer" and the process of "induction" of the embryonic structure and function. Though he may have carried out what came to be seen as definitive experimental work establishing the mechanisms of development, Spemann himself remained something of a vitalist. Like Briggs, Hamburger discovered and laid out the importance of examining and dissecting assumptions. ${ }^{6}$

Finally, Manfred Laubichler and Maienschein have had the pleasure of working with William C. Aird, who is Chief of Molecular and Vascular Medicine at Harvard Medical School. Aird has put together a remarkable book of nearly two thousand pages, really a compendium of everything anybody seems to know about the endothelium. ${ }^{7}$ When he began this project, he asked Maienschein to help coordinate a set of two- to three-page descriptions of the contributions of historical figures to what we now know. This is where many scientists begin with history-with an interest in anecdotes and a sketch of the

\footnotetext{
${ }^{6}$ Viktor Hamburger, The Heritage of Experimental Embryology: Hans Spemann and the Organizer (Oxford: Oxford Univ. Press, 1988).

${ }^{7}$ William C. Aird, ed., Endothelial Biomedicine (Cambridge: Cambridge Univ. Press, 2007).
} 
background to current work. Unfortunately, most scientists end there. Aird did not. Instead, he brought the two of us into the collaboration, and we all began to learn tremendously more than any of us would have alone.

We all discovered, first, that the standard picture of the history of endothelial biology has missed a great deal. That is not so surprising. It also turned out that much of what scientists thought they knew from textbook renditions was either inaccurate or inadequate, and that is not so surprising either. What is surprising is that we began to realize that the very term "endothelium" came from Wilhelm His in 1865, arising in the context of his study of the development of the different tissue layers and in work completely ignored by the textbook representations. ${ }^{8}$

A close look at the history of the science shows that the endothelium was identified as a distinctive tissue with unique functions because of its developmental history. Studying the history makes it clearer that researchers today are ignoring the important origins of the endothelium. History shows that today's attempts to understand the endothelial role in stem-cell development of red blood cells or of pathogenic vascular lining would benefit from study not just of adult vessels but also of the details of embryological development.

This was not obvious until we looked closely at the history. Similarly, Laubichler pointed out that looking not just at humans (which scientists in medical schools and hospitals obviously tend to do), but also at evolutionary relationships with other species, would illuminate the development of the structure and function of the endothelium and of its pathological conditions. Aird is such a fascinating Renaissance man that he has now taken up serious historical study as a result of this collaboration, and he is convinced that this is not a distraction from but, rather, an enhancement of his extremely well-funded and significant scientific work. In this case, the history has made a substantive difference for the science and for the scientist.

\section{EMBEDDING A HISTORIAN IN A LAB}

For over a year, Andrea Loettgers has been part of the group of the synthetic biologist Michael Elowitz at the California Institute of Technology. ${ }^{9}$ What makes this collaboration especially relevant for our investigation of how the history of science can matter to scientists is that it goes beyond the more traditional arrangements in which historians and social scientists have assumed that they can act as detached observers while studying the activities inside laboratories as cases of "science in action." In this case, the historian has become an active participant and collaborator in the ongoing activities of the lab. At the same time, she has contributed to insights into the development of synthetic biology, which in turn have helped to shape a historical project on the role of physical and mathematical models in the life sciences. The collaboration thus goes both ways.

In order to see how history can matter in a cutting-edge field of science, we first need to introduce a bit of context for synthetic biology. The goal of synthetic biology is to understand complex biological systems by building a synthetic model of parts of these systems and subsequently by engineering existing biological systems for new purposes. Methodologically, one starts with an abstract mathematical model that describes-for example- the circadian clock. On the basis of these descriptions, synthetic biologists then

\footnotetext{
${ }^{8}$ Wilhelm His, Die Häute und Höhlen des Körpers (Basel: Schwighauser, 1865), p. 18.

${ }^{9}$ On this research group see http://www.elowitz.caltech.edu/people.html; and D. Sprinzak and M. B. Elowitz, "Reconstruction of Genetic Circuits," Nature, 2005, 438:443-448.
} 
engineer synthetic networks and test their behavior by implementing them into cells. A good example is the Repressilator introduced by Stanislas Leibler and Michael Elowitz in $2000 .^{10}$ The Repressilator models rhythmic behavior and allows researchers to visualize the oscillation in protein production by linking it to the synthesis of a fluorescent green protein. The protein oscillations in individual cells can be recorded using time-lapse movies and later interpreted.

The collaboration with this group started when Elowitz and Loettgers discovered a common interest in the representational relationships between models and biological systems and functions. For Elowitz, this was of immediate practical importance: synthetic biology involves different types of models (mathematical and material) and complex experimental manipulations, such as incorporating into cells artificial regulatory networks that are often difficult to interpret. Furthermore, the whole field of synthetic biology is still viewed with suspicion by large parts of the scientific community. A clear understanding of the underlying assumptions, as well as the limits and possibilities of the new methods, is thus crucial for gaining wider acceptance.

Questions regarding the representational relationship between model and object have been widely discussed by philosophers of science such as Mary Hesse, Ronald Giere, Bas van Fraassen, Mary Morgan, and Margaret Morrison, among others. Given the pressure and competition, however, especially in rapidly moving "hot" fields like synthetic biology, one cannot expect scientists to be aware of this literature. Furthermore, scientists usually do not assume that the history and philosophy of science could be of value for their actual research.

Loettgers's interest in synthetic models grew out of her previous historical work on the Hopfield model, one of the most influential models in neuroscience. ${ }^{11}$ The Hopfield model is closely related to the engineered genetic networks used by synthetic biologists, with both depending on robust interdisciplinarity. In representing structures and functions of biological systems, both modeling approaches use concepts from disciplines outside of biology, such as physics and engineering. In both cases the use of these concepts is critically related to core assumptions about the structures and functions of biological systems.

In the case of the Hopfield model, the critical assumption is that the structure and mechanism represented by the model of a disordered magnetic system is of such a general character that it can also be used in the representation of biological neural networks and functions such as auto-associative memory. Synthetic models are based on the assumption that feedback loops adequately describe the mechanisms of gene regulation. The main difference between synthetic models and the Hopfield model is that the latter is an abstract mathematical model while synthetic models are engineered out of biological components and therefore have the same material composition as the object they represent. Synthetic models are thus hybrid models, combining aspects from abstract mathematical models and experiments. The critical epistemological question that interested Loettgers is how hybrid models can generate empirical evidence for or against the assumptions made in their design that goes beyond the insights already gained by abstract mathematical models.

Surprisingly, another question soon dominated the discussions between Loettgers and

${ }^{10}$ M. B. Elowitz and S. Leibler, "A Synthetic Oscillatory Network of Transcriptional Regulators," Nature, 2000, 403:335-338.

${ }^{11}$ John J. Hopfield, "Neural Networks and Physical Systems with Emergent Collective Computational Abilities," Proceedings of the National Academy of Sciences, 1982, 79:2554-2558. 
the Elowitz group: Can a historian embedded in a laboratory research group contribute to the ongoing research there? The answer turned out to be yes-and in important ways. Analyzing the core assumptions that underlie different modeling strategies-something historians are trained to do-was valuable, since synthetic biologists rely heavily on models and concepts that originate outside the biological sciences. Understanding the limitations and imperfect adaptability of these models-asking, for instance, how the model could incorporate experimental noise of biological systems - turned out to be crucial to progress in the lab. As part of their collaboration, both parties had to become familiar with the different languages and shorthands in their respective fields of synthetic biology and history and philosophy of science, an exercise that took some time and was not always easy but that is essential for any form of interdisciplinary collaboration. This work allowed them to explore the advantages, limits, and relations of the different model types from a variety of different angles. These discussions then became the basis for exploring the limits and possibilities of synthetic models such as the Repressilator.

The lessons of this interaction between a historian and a cutting-edge laboratory in synthetic biology are twofold. First, historical perspectives helped to clarify the assumptions and concepts used in model design and to address the uncertainty inherent in the representational relationships between the engineered model and the regulatory gene networks of biological systems. Second, historical analysis helped to contextualize the specific modeling approach used in synthetic biology. These aspects of interdisciplinary collaboration are interrelated and combine philosophical as well as historical perspectives. They took time and willingness on both sides to invest in understanding each other's language and assumptions, but the results have been transformative.

\section{HISTORY AS INTEGRAL TO THEORETICAL SCIENCE}

Integration of different theoretical perspectives, models, and experimental systems is the bread and butter of interdisciplinary research. And as science becomes increasingly interor transdisciplinary, integration is gaining in importance. Here we argue that in areas of science that involve crossing disciplinary boundaries, the history of the discipline(s), their problems and methods, and, most important, the history of their conceptual development are crucial parts of the science itself. While we think that this is true for all sciences, our discussion is focused specifically on biology and in this example on theoretical biology. ${ }^{12}$

In general, critical historical evaluations are needed because the crucial assumptions and conceptual constraints, the details of the central experimental systems or original formal models, as well as the supporting data and measurements, are generally not included in current or semiaxiomatic formulations of most (biological) theories. It is, therefore, not surprising that many models and theories in biology are currently used mostly pragmatically: scientists tend to know which ones "work" and tend to modify or adapt them to different data rather than reevaluating their fundamental assumptions. However, in cases in which substantial revisions are required, researchers generally go back to the original literature in order to uncover precisely those assumptions that have constrained the model or theory in the past. In this sense, history is an essential part of the avant-garde of biology.

It should come as no surprise that looking at the history of biology as an integral part

\footnotetext{
${ }^{12}$ Manfred D. Laubichler, "The Specter of the Past: What the History of Theoretical Biology Means Today," Biological Theory, 2007, 2:131-133.
} 
of biology has implications for the practice of the history of science. Sarton had already seen the history of science as a pluralistic endeavor, capturing the viewpoints of the historian, the scientist, and the philosopher, respectively. Within each of these (and today there are even more viewpoints involved), the history of biology is presented according to different criteria of interest and relevance. From the point of view of a biologist, as we have seen, history can serve several important functions. Such a history of science will differ from other approaches such as cultural or social history of science. It will be largely a history of concepts, theories, experiments, measurement procedures, assumptions, models, and tools focused on the evaluation of the intrinsic logic of biological concepts and theories and the epistemological questions and assumptions of biology.

We can also rephrase this last point in biological terminology: such an analytical history of biological thinking and practice has a function like that of developing a respectable phylogeny. Only when we know the evolutionary history and relationships can we really understand the detailed features of any particular organism; similarly, only when we understand the evolutionary history and relationships of the concepts and theories of biology within the contexts where they first emerged can we really understand the detailed features of the particular assumptions and practices within science. And, even though many biologists are content to use a phylogeny (whether of organisms or of ideas) that is handed to them, the biologists we have pointed to have come to recognize it as a legitimate and complex scientific endeavor to investigate and establish these phylogenies. They have come to see this historical exercise as serving in many ways as the basis for their biological research and as a foundation of current biology. The history helps provide the necessary context for conceptual innovation and synthesis.

\section{CONCLUSIONS}

We have presented examples where history has made a difference to the science and science to the history. Some are past and some are ongoing projects. Let us look at one example of a central problem in biology where we believe history can, should, and-we hope-will make a difference in informing the science. Gene concepts have received quite a bit of attention from historians of biology, with studies drawing on all three of Sarton's historical, philosophical, and biological "points of view" on a problem. ${ }^{13}$ We see how different conceptions of the gene (as the unit of inheritance, the physical gene, or the physiological or developmental gene) have emerged in the context of specific theoretical problems and experimental practices. The last concept has been part of several research programs aimed at understanding the physiological actions of genes in development, especially the problem of differentiation-a problem that itself has a most illustrious history. Prominent examples include Richard Goldschmidt's studies on sex determination in Lymantria, Alfred Kühn's work on wing patterns and eye coloration in Ephestia, and, more recently, Eric Davidson's work on the regulation of gene expression in development. ${ }^{14}$

\footnotetext{
${ }^{13}$ Peter J. Beurton, Raphael Falk, and Hans-Jörg Rheinberger, eds., The Concept of the Gene in Development and Evolution: Historical and Epistemological Perspectives (Cambridge: Cambridge Univ. Press, 2000).

${ }^{14}$ Eric H. Davidson, The Regulatory Genome (Burlington, Mass.: Academic, 2006); Gerald L. Geison and Manfred D. Laubichler, "Reflections on the Role of Organismal and Cultural Variation in the History of the Biological Sciences," Studies in the History and Philosophy of the Life Sciences, 2001, 32:1-29; and Laubichler and Hans-Jörg Rheinberger, "Alfred Kühn (1885-1968) and Developmental Evolution," Journal of Experimental Zoology, Part B: Molecular and Developmental Evolution, 2004, 302:103-110.
} 
Yet the biological research remains dispersed in different labs and focused on different

aspects of heredity and development. Arriving at a comprehensive theory that connects genes with development and evolution is one of the main challenges of biology today, as seen in Evo Devo programs. However, substantial stumbling blocks remain. Different assumptions and practices present barriers, as do the different languages of different disciplines. Loettgers's work within a lab pursuing cutting-edge biological research, and the concomitant demonstration of the necessity of history for theory and the value of history in uncovering assumptions and helping facilitate translations, shows that history can help. By working with biologists, rather than simply in their own silos, historians of science can help identify and interpret the original assumptions and constraints underlying different models, theories, and practices-by providing an analytical history of both.

To conclude, our briefly sketched examples support the thesis that the history of biology "from the point of view of the scientist" is an integral part of biology (and science more generally), has already contributed to current attempts to establish new theoretical perspectives, and has great potential for contributing in many additional ways. If this happens on a larger scale it will transform not only science but the discipline of the history of science as well. 